\title{
CARACTERÍSTICAS DE LA INFORMALIDAD EN EL TRANSPORTE DE PASAJEROS EN SANTIAGO**
}

\author{
PATRICIO DE LA PUENTE LAFOY, EMILIO TORRES ROJAS
}

\section{PLANTEAMIENTOS DEL PROBLEMA}

La informalidad representa un tipo de actividad laboral desempeñada al margen de las disposiciones legales vigentes, aunque no necesariamente en oposición a ellas, que se efectúa mediante el empleo de resquicios, argucias o acciones no constitutivas de comportamientos antisociales en sí mismos, por cuanto se despliegan para alcanzar metas socialmente legítimas. Ellas constituyen formas adaptativas utilizadas generalmente por los sectores más pobres de la población, como una forma de ganarse la vida y satisfacer sus necesidades básicas.

En el caso de la informalidad en el transporte de pasajeros Amstrong (1987), señala que éste constituye un sistema paralelo al formal que tiene lugar a través de vehículos pequeños que funcionan de manera no estructurada y que en ocasiones representa una alternativa al transporte reglamentado de microbuses en los países en desarrollo.

Los móviles empleados suelen tener diversas formas y denominaciones: las "rickshas" en Nueva Delhi, son vehículos motorizados a pedal; Ios "matatus" en Nairobi, son pequeños furgones convertidos; los "jeepneys" en Manila, son jeeps convertidos; los "dolmus" en Estambul, son especies de taxis compartidos; los "públicos" en Puerto Rico, son minibuses y los "microbuses" en Lima, comprenden una variedad de vehículos que incluyen desde las camionetas rurales tipo Kombi (Kleinbus) o Van hasta los D 300, D 500, BB-57, Scania y GMC.

Estos sistemas de transporte urbano se caracterizan por la gran gama de servicios que ofrecen: entre otros se pueden mencionar los personalizados - puerta a puerta-, los compartidos en recorridos fijados por los pasajeros mismos y los regulares que siguen rutas definidas. Otra de las neculiaridades de la informalidad en el sector lo constituye el hecho que los empresarios pueden :legir libremente el tipo de vehículo a utilizar, las trayectorias, las frecuencias e incluso las horas le funcionamiento. No siempre están en situación de fijar las tarifas, ya que en algunas ciudades durante ciertos lapsos, ellas son establecidas por las autoridades; sin embargo, disponen de : lexibilidad para adaptarse a los cambios de la demanda, generando nuevos recorridos o extensiéndolos.

Los vehículos pequeños tienen la ventaja de penetrar por pequeñas callejuelas propias de las sreas céntricas de las ciudades y de sectores residenciales periféricos. Sus dueños suelen ser equeños empresarios que compiten arduamente entre sí por la captura de pasajeros, imponiendo - on su actividad una carga mínima al fisco.

Según este autor, su existencia y desarrollo es complementario al sistema formal, permitiendo .umentar la capacidad de transporte urbano en las horas punta, siendo además ventajoso en zonas londe la demanda es insuficientemente satisfecha por las grandes flotas de ómnibuses.

Este sistema paralelo, en algunos países puede llegar incluso a desplazar el transporte formal

\footnotetext{
*Este artículo se basa en resultados obtenidos mediante la realización del proyecto FONDECYT N 579-89 “Una teoría bre las áreas fronteras entre la ciudad y el mundo de la pobreza urbana" efectuado por un equipo interdisciplinario de : vestigadores pertenecientes al Instituto de Estudios Urbanos de la Pontificia Universidad Católica de Chile y al spartamento de Sociología de la Universidad de Chile, compuesto por los señores Fernando Riveros R. (Investigador sponsable); Jaime Matas C.; Patricio de la Puente L. e Ignacio Santa María s.c. (coinvestigadores).
} 
de pasajeros. Así en Lima, de acuerdo a estudios efectuados por I.L.D. - Instituto Libertad y Democracia- el parque vehicular informal destinado al transporte público alcanzaba en 1984 al $95 \%$, concentrando sus recorridos hacia los sectores más populares de la ciudad, dejando el servicio de pasajeros en los barrios tradicionales entregado a los buses estatales y a compañías privadas.

El transporte informal de pasajeros aparece regido por una normativa extralegal que regula el derecho de propiedad de las máquinas y la organización. La generación de esta modalidad se generó mediante la invasión de rutas por avenidas y calles, de acuerdo a la demanda de la población, siendo los recorridos establecidos mediante criterios de conveniencia económica, lográndose a veces su reconocimiento oficial mediante negociaciones con el Estado. En la medida que estas rutas incrementan su importancia los informales tienden a organizarse, negociar e incluso enfrentarse a las instituciones legales. Dichas organizaciones se desarrollan en tres niveles; los comités, que reúnen a los transportistas informales que operan en una misma ruta; los sindicatos, que agrupan a diversos comités y, por último, las federaciones que reúnen a los distintos sindicatos de la ciudad. Cada organización cumple diversas funciones, siendo las más importantes proteger a los afiliados mediante créditos, préstamos o seguros mutuales, organizar la explotación de las rutas y actuar como grupo de interés para negociar con el sector público de acuerdo a concesiones recíprocas.

Las funciones de orden público-administrativo, tales como reconocimiento legal de derechos, fijación o control de tarifas y, en general, las negociaciones de determinadas garantías por parte del Estado las realizan los sindicatos y las federaciones. Los procedimientos utilizados son los apoyos recíprocos, las amenazas, el uso ocasional de la violencia, huelgas y marchas, entre muchos otros mecanismos de presión.

Según un estudio de Hernando de Soto (1986) la informalidad en el sector transporte colectivo urbano sería más atractiva que la actividad formal. En Perú la tramitación legal para que una empresa de ómnibuses o microbuses obtenga el reconocimiento necesario demora unos veintiséis meses; este solo hecho ya incide en la preferencia de los empresarios por elegir vías informales.

Ahora bien, la enorme presencia de la informalidad en el transporte urbano de pasajeros en ese país ha provocado que el tránsito sea uno de los más caóticos y peligrosos del mundo, acarreando enormes costos materiales y vidas humanas. En 1984, se calculó que las pérdidas alcanzaban a nueve millones de dólares y más mil quinientas muertes por accidentes del tránsito. La sensación de inseguridad de los pasajeros en obtener un medio de locomoción que los traslade desde sus hogares a sus trabajos acarrea, por cierto, que se pierdan diariamente varias horas laborales, con el consiguiente perjuicio no sólo para las personas involucradas sino para la economía en general.

Por otra parte, las trabas burocráticas desalientan la profesionalización de la actividad y desincentiva la renovación del parque automotor. Si una empresa de transporte informal progresara, aumentara su tamaño y modernizara la dotación de vehículos se tornaría muy visible para las autoridades; de allí que las organizaciones tiendan a mantener dimensiones reducidas, con la consiguiente imposibilidad de hacer economías de escala.

Si bien es cierto los planteamientos de $\mathrm{H}$. de Soto representan un valioso aporte al tema de las actividades informales y a la informalidad en el transporte público, sus esquemas parecen adecuados a la realidad histórico-contingente peruana y no a situaciones que presentan otras características como es el caso de Santiago de Chile donde el transporte informal no representa un segmento social importante.

Lo anteriormente no significa que no se presenten modalidades de informalidad en el sistema de transporte en nuestro país. Por el contrario, formas recurrentes muchas veces encubiertas son 
posibles de detectar a diario en la ciudad, sin que hasta el momento se cuente con investigaciones sistemáticas sobre el tema.

\section{OBJETIVOS Y METODOLOGÍA DE LA INVESTIGACIÓN}

El objetivo central de la investigación consistió en conocer las modalidades del transporte informal de pasajeros que se registra en la ciudad de Santiago, ya sea que se realice por medio de buses, taxis básicos, taxis colectivos u otros vehículos.

La identificación de los diversos tipos de informalidad en el transporte urbano tuvo como propósitos:

a) conocer las áreas de contacto o de frontera que permiten la articulación entre la actividad formal e informal del transporte efectuado mediante los diversos móviles.

b) determinar las normas que rigen la actividad formal de transporte y las formas de adaptación que de ellas realizan los informales para actuar en Santiago.

c) conocer los sectores de la ciudad en que se desarrollan o localizan las actividades de transporte informal, estableciendo posibles pautas de recorridos.

d) establecer la existencia de obstáculos que impidan o dificulten el desarrollo de una actividad formal en el sector.

En orden a lograr estos objetivos se diseñó un estudio de carácter exploratorio, utilizándose como técnica de recolección de datos fundamental la entrevista, por cuanto es un recurso particularmente apropiado de emplear cuando se pretende obtener un conocimiento básico del que se carece sobre la población de estudio, así como en el caso de una investigación que aborda un tema complejo que asume modalidades diversas en un universo muy heterogéneo.

Entre las diversas clases de entrevistas se escogió aquélla menos estructurada -la entrevista libre - que permite a los entrevistados manifestar espontáneamente sus vivencias, a través de opiniones y deseos respecto de un tema determinado, a través de una conversación con un entrevistador. Su flexibilidad permitió abordar el tema sin estar previamente sujeto a esquemas preestablecidos y conseguir una atmósfera sin tensiones que permitiera a los entrevistados referirse a conductas que muchas veces bordeaban la ilegalidad, cuando no infrinjían la ley abiertamente.

Los entrevistados fueron contactados personalmente durante el segundo semestre de 1989 por los autores de este artículo, siendo la entrevista efectuada por ellos mismos en los lugares de trabajo garantizándose el anonimato de sus respuestas, las que fueron recogidas mediante registro magnetofónico a objeto de conseguir el máximo detalle y precisión.

Como sucede en todo diseño exploratorio, el número de entrevistas realizadas no fue fijado de antemano. Los entrevistados fueron seleccionados en función de su conocimiento sobre el tema, diversidad de experiencia y puntos de vista y antigüedad en el oficio - siendo generalmente identificados por otros informantes previamente entrevistados-, ya sea que desarrollaran actividades formales en el transporte urbano santiaguino o desempeñaran cargos directivos en alguna asociación gremial $\mathrm{u}$ organización del sector. Adicionalmente, se entrevistó a funcionarios pertenecientes al Ministerio de Transportes y Comunicaciones, a fin de conocer la normativa vigente que regula esta actividad y aspectos generales del problema.

La información recogida permitió clasificar y caracterizar las diferentes modalidades de la informalidad detectada, permitiendo describir los rasgos más relevantes de cada tipo, su localización en algunos puntos de la ciudad, sus interacciones con la formalidad y algunas pautas culturales que orientan el comportamiento de las personas que desempeñan estos trabajos.

Si bien se obtuvo un gran caudal de información significativa, el proyecto de investigación 
no se proponía elaborar un mapa exhaustivo de la ubicación, recorrido e interacciones del transporte informal en la ciudad de Santiago. Ello hubiera implicado la utilización de un diseño de investigación descriptivo y del acopio de antecedentes cuantitativos, fases que no pueden realizarse sin un conocimiento exploratorio previo.

Como es sabido, a diferencia de los resultados obtenidos de la aplicación de encuestas masivas, la información recopilada mediante entrevistas no precisa de análisis con vistas a un tratamiento estadístico y computacional. Su valor radica precisamente en la singularidad y detalle de las respuestas conseguidas, en la amplitud de las descripciones y en las sugerencias de pistas que provea.

Las respuestas más sugerentes fueron en parte trasliteradas, recurriendo de manera complementaria a informaciones emanadas de otras fuentes, como artículos publicados en revistas especializadas, documentos de trabajo, informes técnicos y material periodístico aparecido en la prensa capitalina.

\section{ANTECEDENTES SOBRE POLÍITICAS DE TRANSPORTE COLECTIVO EN SANTIAGO}

Tradicionalmente en Chile, el Estado ha tenido una presencia directa en el transporte de pasajeros a través de la Empresa de Transportes Colectivos que disponía de tranvías, microbuses y trolleybuses. Durante el gobierno pasado se aplicó un modelo económico social tendiente a liberar los mercados, a modo de conseguir una mayor competencia entre productores de bienes y servicios. El esquema de libre mercado se aplicó asimismo al sector transporte que era uno de los mercados más controlados con características monopólicas, donde la libertad de trabajo era coartada por numerosas restricciones al ingreso de nuevos oferentes, produciéndose un mayor costo para los usuarios por medio de tarifas inás altas o servicios deficientes.

Desde los inicios del gobierno militar se implementó una política encaminada a liberalizar el mercado de transporte urbano, permitiendo la incorporación de nuevos móviles a la locomoción de pasajeros mediante la disminución de una frondosa legislación burocrática. Así, se autorizó la libre importación de vehículos, de cualquier procedencia y tipo; se liberó el acceso a la actividad de taxista colec tivo o individual, conjuntamente con la libertad tarifaria; la liberación de recorridos de buses y taxibuses y de sus tarifas.

Sin embargo, desde 1981 se constata un cambio en esta tendencia libre mercadista por vías administrativas. Un ejemplo de ello lo constituye la Resolución № 1 del Ministerio de Transporte y Comunicaciones, aparecida en el Diario Oficial del 1 de febrero de 1984, que restringe la creación de nuevos recorridos de buses y taxibuses y el ingreso de nuevos vehículos (buses, taxibuses y taxis).

Esta restricción a la libre competencia ha favorecido, según algunos economistas, las tendencias monopólicas en el sector.

Para que exista un monopolio deben cumplirse ciertos requisitos entre los cuales se cuenta: un número de empresarios que fijen y respeten ciertos acuerdos; que el producto o servicio sea homogéneo para reducir la probabilidad de que los miembros del monopolio trasgredan los acuerdos; la existencia de una demanda inelástica que sea relativamente estable en el tiempo y la generación de barreras que impidan el ingreso de nuevas empresas, ya sean legales o naturales.

De este modo, la configuración de un monopolio se expresa socialmente en un grupo de presión que demanda a la autoridad ciertos beneficios a cambio de determinadas concesiones, en orden a modificar la legislación para fortalecer la permanencia del monopolio.

Ugarte y Vatter a través del análisis de tres factores - precios, antecedentes legales y 
determinadas acciones empresariales - arriban a la conclusión que, a partir de 1981, se han ido configurando modalidades no competitivas en el transporte de pasajeros de la ciudad de Santiago dando origen a la organización de un cartel.

Así, en relación al factor precio, los autores demuestran que entre 1981 y 1987 el aumento de las tarifas de la locomoción colectiva en la capital ha sido superior al incremento de sus costos; tal es el caso de la bencina y especialmente del restos de los insumos, produciéndose una diferencia o renta que los mecanismos de mercado no han logrado disminuir a través del tiempo.

En cuanto a las barreras que se han establecido para dificultar e incluso impedir el ingreso de nuevos oferentes, se señalan las siguientes evidencias legales:

a) El Decreto № 100, del 29 de septiembre de 1982 (Ministerio de Transporte y Comunicaciones) que prohíbe el ingreso de microbuses al área céntrica de Santiago, además de proscribir la incorporación de vehículos de distinta clasificación a los ya existentes en el parque vehicular.

b) La Resolución № 1, de1 3 de enero de 1984 (Ministerio de Transporte y Comunicaciones), que impide la creación de nuevos recorridos o el tránsito de nucvos vehículos en vías congestionadas o próximas a serlo; estipulando además que, para la creación o modificación de un recorrido, se podrá solicitar la opinión de las asociaciones gremiales o a las líneas que se encuentren directamente afectadas con la eventual configuración de nuevas rutas.

c) Con posterioridad, el 21 de febrero de 1986, la Subsecretaría de Transportes prohibió en la práctica el ingreso de nuevas máquinas y la creación de nuevos recorridos, por cuan to se estableció la modalidad que sólo se incorporaría un vehículo nuevo cuando fuera retirado de circulación uno antiguo.

Este conjun to de reglamentaciones ha contribuido a configurar un cartel que está en situación de regular las tarifas del transporte público urbano al tener una fuerte capacidad de presión ante las autoridades.

Entre los hechos que revelarían la presencia efectiva de un grupo de presión en el sector, los autores mencionan el paro de locomoción colectiva ocurrido el 1 de junio de 1987, que fue zonvocado por las asociaciones gremiales y obedecido unánimemente, demostrando con ello una notable capacidad organizativa, cohesión y una clara conciencia sobre sus intereses. Como consecuencia de dicha huelga, las asociaciones obtuvieron una ampliación del ámbito de la restricción vehicular para la locomoción colectiva a todo Santiago, que antes había operado xxclusivamente en el radio central, reduciendo la oferta artificialmente lo que constituye un mecanismo beneficioso para el sector, dada la existencia de un sobrestock del parque vehicular de buses y taxibuses.

Como consecuencia de la reacción de la opinión pública, manifestada mediante artículos omo los reseñados, de cartas del público aparecidos en la prensa capitalina que denunciaban estas nomalías al sistema de libre mercado imperante, se dictó la ley 18.696 del 31 de marzo de 1988 a cual liberó las restricciones reglamentarias que se habían ido constituyendo, al permitir la libre inportación de vehículos nuevos o usados de cualquier tipo, ya sea que se destinen a la novilización pública o privada, individual o colectiva en todo el territorio nacional, señalando que o se requerirá de autorización alguna para desarrollar la actividad, con excepción de aquellas - inculadas a evitar el aumento de la contaminación del aire en Santiago, lo que implica revisiones - rriódicas, restricciones vehiculares en determinadas épocas del año (otoño e invierno) y además, a celebración de un contrato de seguro obligatorio general que cubre daños a las personas ante el SE - Instituto de Seguros del Estado-o ante cualquier compañía privada aseguradora del país - Je disponga de este servicio. En esta misma ley se consagra la libertad de recorridos, en términos je cualquier persona que disponga de un vehículo para la locomoción colectiva puede elegir la ta que estime conveniente, establecer nuevas variantes respecto de las existentes o inaugurar 
nuevos, sin necesidad de solicitar licencias especiales para ello. Con anterioridad a la entrada en vigencia de estas disposiciones, se requería una autorización del Ministerio de Transporte y Comunicaciones para alterar los recorridos previamente sancionados por esa misma repartición pública.

Durante el actual gobierno se advierte un cambio en la orientación de la política de Transporte Urbano. E1 28 de junio de 1990 el Ministerio de Transportes y Telecomunicaciones informó a todos los actores y a la opinión pública en general, lineamientos centrales sobre el transporte público urbano de superficie señalándose como diagnóstico global que éste atravesaba por una de las peores crisis de su historia, producto de una total desregulación aplicada al sector en el pasado régimen. Por tal motivo, se planteó que la premisa básica de la nueva administración, sería retomar el rol normativo y regulador del Estado sobre todo en un sector donde no posee servicios propios, estando el mercado por completo en manos de operadores privados.

De acuerdo con dicho espíritu el Ministerio ha planteado iniciativas que han suscitado la reacción de diversos grupos vinculados con el sector, desatando confrontaciones polémicas especialmente durante este último año. En primer término, se envió al Parlamento un proyecto de ley modificatorio del artículo 3 de la ley 18.696 por estimarse que acarreaba graves distorsiones para la circulación de vehículos especialmente en zonas urbanas. Dicho proyecto fue aprobado por el Congreso Nacional promulgándose la ley 10.011 que ordena y reglamenta la actividad del transporte público y el uso de vías.

Esta nueva Ley termina en la práctica con la llamada "libertad de recorridos" prevaleciente hasta entonces, al establecer restricciones para cl uso de calles, creación de nuevos recorridos y otras disposiciones que limitan la utilización de cierto tipo de vehículos.

Además se ha impulsado un plan de reducción del parque de locomoción colectiva en Santiago y de fijación de antigüedad máxima permitida para los vehículos el cual se está llevando a la práctica mediante dos instrumentos legales. Uno establece un calendario de retiro de vehículos de la locomoción colectiva, dejando como límite de antigüedad 18 años para Santiago, San Bernardo y Puente Alto y 20 años para el resto del país; otro que faculta al Estado a adquirir máquinas modelo 1973 o anteriores. El retiro de 2.600 buses y taxibuses producto de esta compra, constituyó la primera confrontación importante entre los gremios de transportistas y el actual gobierno, aún cuando el proceso finalizó dentro de los límites originalmente proyectados por el Ministerio de Transportes y Telecomunicaciones.

Con el propósito de cerrar algunas brechas en la legislación que según las autoridades contribuían a agravar imperfecciones en el transporte de pasajeros, se tramitó ante el Parlamento un proyecto que modifica el artículo № 43 de la ley 18.290, referido a la inscripción de vehículos. Dicha reglamentación pretende evitar la inscripción como nuevos de vehículos antiguos reacondicionados, o de vehículos armados con piezas y partes usadas no aptos para prestar servicios de transporte de pasajeros. En forma complementaria, se modificó el artículo № 21 de la Ley 18.483 , prohibiendo la "importación de partes y piezas usadas con la finalidad de aumentar la seguridad de los pasajeros y reducir la contaminación ambiental.

El conjunto de estas medidas no sólo propenden a que el Estado reasuma su función reguladora del transporte de pasajeros sino que en su fundamento la actual política pretende otorgar prioridad al transporte público desincentivando la utilización indiscriminada del automóvil privado, sobre todo, en las horas de mayor congestión y en las vías de alta circulación.

De todas las disposiciones contenidas en las nuevas normativas, sin duda, la que ha provocado mayor conflicto entre los actores públicos y privados es la referida a la licitación de las calles céntricas de la ciudad, respecto de la cual se ha centrado la polémica durante 1991. Las negociaciones iniciales entre autoridades ministeriales y las asociaciones de Dueños de Buses y 
Taxibuses, no arrojaron acuerdos, generando la ruptura del diálogo en varias oportunidades, producto de la negativa de estos últimos para participar en la licitación.

De las descalificaciones mutuas se pasó a acciones unilaterales que por parte del sector empresarial culminaron en protestas y llamado a una paralización de actividades que tuvo lugar el día 10 de septiembre. Como respuesta el gobierno modificó las bases de la licitación haciéndola extensiva a empresas extranjeras, lo cual produjo finalmente un nuevo acercamiento y una aceptación de los empresarios para participar en las propuestas. Como resultado de estos acontecimientos el Ministro de Transportes y Telecomunicaciones espera que el sistema de licitación de calles esté en pleno funcionamiento durante 1992.

Para ello, se privilegiará la utilización de vehículos de alta capacidad en corredores de gran demanda, para evitar la congestión vehicular, se preferirá aquellos móviles de reciente fabricación para reducir el riesgo de accidentes y la emisión de contaminantes, se procurará la existencia de servicios diferenciados en función del tipo de demanda (expresos, buses, taxibuses, trolleys), además se procurará incrementar la integración entre los distintos medios, con el fin de evitar la competencia desleal que conduce a la ineficacia y al pago de doble tarifa.

El transporte urbano de pasajeros mediante taxis básicos y colectivos también ha experimentado transformaciones en cuanto a las características de sus organizaciones, como consecuencia de las normativas referentes a la libertad de asociación gremial.

En la actualidad ningún trabajador está obligado a afiliarse a un sindicato. Esta facultad prevista en la institucionalidad vigente se ha trasuntado en el área de las asociaciones de taxistas cn la pérdida de control de dichas asociaciones sobre las personas que desarrollaban este tipo de actividades, disminuyendo su número de afiliados, la capacidad de gestión y de presión ante las autoridades político-administrativas.

Durante los gobiernos anteriores al de las Fuerzas Armadas si una persona deseaba desempenarse como taxista debía necesariamente incorporarse a una organización sindical, la cual la obligaba a cumplir ciertos requisitos. Con la actual situación, inspirada en la libertad de trabajo y la libre asociación, no existen impedimentos para "taxear", lo que ha acarreado una saturación del parque vehicular destinado al transporte urbano.

Tal vez una manifestación del escaso poder de presión de las organizaciones de taxistas lo constituye el hecho que las tarifas estén fijadas por el Ministerio de Transporte y Comunicaciones, existiendo sólo grados de libertad para establecer el precio de la "bajada de bandera" - o cobro inicial— que los conductores pucden establecer dentro de una franja o rango permitido.

Sin embargo, en agosto de 1989 , mediante el Decreto № 124 del Ministerio de Transporte se estableció la plena libertad a los empresarios de taxis para fijar los valores de los pasajes, liminando virtualmente los cobros adicionales en horarios nocturnos y en días festivos. Dicha Jisposición estipula sanciones a quiénes no anuncien los valores de "bajada de bandera" y la tarifa ustablecida para cada doscientos metros.

Según declaraciones aparecidas en la prensa, las asociaciones de taxistas han declarado que ista legislación permite aumentar la competencia y brindar un mejor servicio, al obligar a los umpresarios a mantener los automóviles en mejores condiciones.

En términos formales, la reglamentación no discrimina entre los taxis básicos y los colectivos. En ambas situaciones los vehículos deben ser de modelos posteriores al año 1973, hacer los rámites de inscripción y obtener el permiso ministerial, lo que implica generalmente lapsos breves cumplir con una revisión técnica y de gases periódicamente para circular.

Durante el actual gobierno determinadas medidas orientadas a atenuar los altos índices de - ontaminación del aire y a descongestionar el centro de Santiago han limitado la actividad de los axistas. Es así como se ha producido la circulación de los taxis en áreas perimetrales al centro que 
se amplían en las "situaciones de preemergencia además, desde abril del presente año para ingresar a estas zonas céntricas se requiere que los taxis sean de modelos posteriores a 1980 y de una cilindrada de 1.500 c.c. o superior, impidiéndose que los taxis colectivos cuenten con terminales en un determinado radio circunvalar al centro capitalino, y determinándose además recorridos específicos en orden a evitar su circulación por vías altamente congestionadas.

Las sucesivas resoluciones administrativas han sido resistidas por los taxistas, en especial por quienes sirven la línea hacia Maipú. Sin embargo, en términos generales ellas se han cumplido en la práctica.

\section{PECULIARIDADES DEL TRANSPOR'TE INFORMAL EN SANTIAGO}

En esta sección se examinarán las modalidades que asume la informalidad ya sea que se realicen en buses ("micros"), taxibuses ("liebres"), taxis colectivos y taxis básicos.

\section{A. La informalidad en buses y taxibuses}

En la ciudad de Santiago, la totalidad de las líneas de recorridos de la locomoción colectiva están servidas por una gran cantidad de medianos y pequeños empresarios que realizan su labor ajustándose a las disposiciones legales, si bien es posible identificar una gran variedad de acciones legales y actividades tendientes a burlar algunas normas específicas al tránsito público y a la legislación del trabajo.

Los diferentes empresarios dueños de buses se han organizado en "líneas" que son recorridos que unen sectores residenciales localizados en las diversas Comunas de Santiago, siguiendo una pauta que cruza el centro de norte a sur o de este a oeste y viceversa. Con el transcurso del tiempo, la expansión del área urbana de la capital ha dado origen a variantes en la mayor parte de las líneas originales. Cada variante requiere para funcionar de la habilitación de una infraestructura física y administrativa, consistente en un espacio destinado a paraderos de los vehículos en cada terminal, construcción de garitas, pequeñas oficinas en donde se mantienen las plantillas que permiten el control de los microbuses, en cuanto a corte de boletos, tiempos de los recorridos, frecuencia de las "salidas"; en las cuales trabaja personal administrativo, inspectores, secretarias, aseadores, etc.

Los empresarios pertenecientes a cada variante deben financiar estos servicios que se entiende contribuyen a ordenar la actividad en beneficio de todos. Es así como en cada una de ellas convencionalmente se cobra un "derecho de incorporación", consistente en el pago de una suma variable - desde cien mil a un millón de pesos, o más- según sea la rentabilidad del recorrido.

Si bien este mecanismo no está establecido en ley alguna, constituye en el hecho una restricción al trabajo en el transporte de pasajeros, por cuanto dado el sobredimensionamiento del parque vehicular, es muy difícil crear una línea que preste servicios a un área urbana no servida. Por tanto, si una persona inicia actividades con su vehículo sin incorporarse a una línea establecida será considerado en la práctica como un invasor y se verá sujeto a presiones de los otros autobuseros.

Dichas presiones están destinadas a impedir al nuevo competidor recoger pasajeros -al enviarse varios microbuses que anteceden su trayectoria- hacerle "encierros" que entorpezcan su circulación, "toparle" la máquina e incluso amenazar su integridad lísica. En definitiva, ante el riesgo de quebrar en su actividad o de sufrir algún "accidente", todos los empresarios terminan adscribiéndose a alguna línea.

Estas prácticas son ampliamente conocidas, acatadas y vigentes, generando una subcultura con determinadas normas y actitudes que se encuentran fuertemente arraigadas entre quienes desarrollan labores en esta área. 
Parece reforzar estos usos el hecho que la actividad de transporte de pasajeros en Santiago sea, a juicio de los entrevistados, "generacional"; es decir, la gran mayoría de los actuales choferes de la locomoción colectiva son hijos y nietos de empresarios o choferes. Este hecho ha conllevado que las asociaciones que los agrupan se rijan predominantemente por pautas particularistas, donde sus integrantes están relacionados, además de lazos funcionales, por vínculos familiares o de amistad, siendo una tónica de ellas la lealtad al grupo, la cohesión y los sentimientos de solidaridad que se trasuntan en diversas acciones de ayuda mutua.

Una práctica que otrora representaba una actividad informal estaba constituida por los viajes realizados fucra de los recorridos de una línea sin solicitar ni pagar el permiso correspondiente, requisito que se derogó con la entrada en vigencia de la ley 18.696 del 31 de marzo de 1988.

Los viajes fuera de recorrido más frecuentes son aquellos realizados con ocasión de fiestas religiosas que tienen lugar en localidades próximas a la capital. Tal es el caso de las festividades de Pelequén, Andacollo y Lo Vásquez, para las cuales la clientela, constituida tanto por feligreses como por comerciantes, tratan verbalmente con los choferes que realizan esta actividad. Los puntos de contacto entre el cliente y el actor informal son las cercanías de Iglesias, Parroquias o Sedes Sociales localizadas en poblaciones populares.

Otra fuente de traslado de personas fuera de Santiago son las efectuadas por microbuses hacia las playas de la costa central en temporadas de verano.

Este último tipo de viajes, según un informante, comenzaron hacia 1945 como una derivación de aquéllos que efectuaban equipos deportivos de fúlbol. En esa época, como no siempre los deportistas encontraban cupos disponibles en los buses establecidos, comenzaron a asegurar sus pasajes, contratando a microbuses particulares por una cifra que se establecía de común acuerdo. Esta modalidad resultaba más barata y permitía a los equipos de la capital cumplir sus compromisos en los campeonatos en que intervenían con otros clubes en localidades vecinas. Estos viajes se hicieron cada vez más frecuentes para trasladar veraneantes, de preferencia a Cartagena, localizándose los vehículos que sirven esta ruta estratégicamente en las proximidades de la Estación Central de ferrocarriles. La salida de estos microbuses llamados "piratas" no tienen horario fijo, emprendiendo los viajes cuando cuentan con un número de pasajeros suficientes.

Una tercera modalidad en que los vehículos de locomoción colectiva de Santiago no cumplen con los recorridos formales, son los viajes que se efectúan al Estadio Nacional con motivo de algunos partidos de fútbol importantes. Otras modificaciones de las rutas que ocasionalmente ocurren son aquellas destinadas a trasladar a grupos de trabajadores de algunas empresas, y las alteraciones de los recorridos que se producen con el fin de captar un mayor número de pasajeros, acortando el trayecto o realizando el llamado "tony" o "enchufe", que consiste en devolverse a su punto de origen sin haber completado el recorrido formal. Esta argucia no presenta una pauta definida siendo más frecuente al parecer en los sectores periféricos de la ciudad.

Ocasionalmente los choferes utilizan los vehículos fuera de línea para efectuar diligencias particulares o hacer favores a parientes o amigos. De acuerdo a nuestros informantes, esta modalidad se produce después de la jornada de trabajo contratada y nunca en horas de intenso tránsito.

Ya en el terreno de las abiertas irregularidades se pueden mencionar algunas acciones de antigua data que han sido imposible erradicar. Tal vez las más conocidas sean las ganancias extraordinarias que obtienen los choferes cuando "olvidan" dar a los pasajeros el boleto correspondiente o cuando les entregan boletos devueltos previamente por otros pasajeros, práctica que recibe popularmente el nombre de "palomita". También ocurre con frecuencia el hecho que el chofer entregue a los pasajeros la mitad del boleto, consiguiendo de esa forma doblar su porcentaje. Además, se ha detectado la presencia de niños que recolectan boletos en vehículos, e 
incluso en la vía pública, que son vendidos disimuladamente en cajas de fósforos a los conductores, quienes los reutilizan con nuevos pasajeros.

Cabe consignar que en la actualidad el boleto de pasaje ya no es una "especie valorada" representando sólo un medio de control de los empresarios sobre sus empleados. Las irregularidades descritas no son propiamente "prácticas informales", sino que representan un delito de estafa sancionado por la legislación del tránsito.

En relación a estos problemas existen dos visiones contrapuestas. Los empresarios, por su parte, opinan que los conductores requieren estar muy controlados en su actividad, por cuanto siempre tienden a obtener ganancias extraordinarias por medios ilícitos; de ahí que necesiten contratar inspectores que lleven planillas detalladas sobre los boletos adquiridos y utilizados en cada recorrido. Los choferes en cambio, según respuestas emanadas de directivos de asociaciones de conductores de vehículos de locomoción colectiva, atribuyen estas anomalías al sistema de trabajo imperante en el sector, señalando que debido a que los choferes no tienen una formación profesional, los empresarios se aprovechan de esta situación bajando los porcentajes de ganancia de los conductores por boleto cortado. De este modo, las "entradas extras" son percibidas como una mera compensación a la que los conductores "tendrían derecho" a recurrir. Asimismo estas irregularidades también involucrarían a los empresarios cuando algunos de ellos no hacen contratos de trabajo, eluden el pago de las imposiciones o despiden sin previo aviso.

En palabras de uno de los choferes entrevistados:

El empresario, mientras uno le lleve plata está contento, pero uno es el que queda "tiritón". Uno tiene que pactar las ganancias con el empresario. Entonces hay que andar corriendo. Hay muchos choferes que se levantan a las tres de la mañana para tener la mejor ubicación y así andar todo el día en la mejor hora. Uno se arriesga a que lo "cogoteen", porque es uno mismo el que le entrega la plata al empresario.

Tampoco se respetan los años de trabajo y si a uno lo echan no se puede alegar. Mi patrón me debe 13 meses de imposiciones, pero estoy seguro que si voy a reclamarle me "corta", así que tengo que hacerme el "gil".

El noventa por ciento aquí no está al día en las imposiciones, pero cuando a uno le pasa algo (una enfermedad o accidente), se preocupan.

Con el contrato pasa lo mismo: lo hacen cuando ellos (los empresarios) quieren. A veces pasa un año y recién hacen el contrato.

Los imcumplimientos recíprocos de la legislación laboral y del tránsito se ven favorecidos por la complejidad de las tareas de control. Por una parte, es antieconómico para los empresarios contratar un gran número de inspectores que estén en situación de evitar siempre las irregularidades de los conductores; por otra, la legislación vigente contribuye a que prevalezca desorden en cuanto al cumplimiento de las normas laborales y previsionales por parte de los patrones. La Inspección del Trabajo no dispone de personal suficiente para fiscalizar a los miles de empresarios que operan en Santiago el acatamiento oportuno y cabal de la legislación.

A juicio de un representante de la asociación gremial de choferes:

El sistema en que se basa la locomoción colectiva es malo, porque la base del porcentaje del boleto cortado incentiva la competencia entre compañeros de trabajo y entre las diferentes líneas para ganar más pasajeros. Esto hace que el chofer esté presionado, produciéndose carreras, infracciones de tránsito, irregularidades con los pasajes, en fin.

Sería preferible tener un sistema de sueldos que estableciera categorias por antigüedad y capacidad en el oficio". 
Mediante otras entrevistas se ha podido verificar que los choferes preferirían esta modalidad de trabajo, siempre y cuando se cumplan algunos requisitos:

Si a nosotros nos dijeran que vamos a ganar unos ochenta o noventa mil pesos mensuales nos conviene y el empresario que haga lo que quiera (con sus ganancias). Yo andaría tranquilo y no tendría que pasar los 50 kilómetros (por hora).

Otras infracciones a la legislación del tránsito que suelen efectuarse son, por cjemplo, la conducción de buses de locomoción colectiva por choferes que no poseen la licencia tipo "A", obligatoria para manejar este tipo de vehículos. Según declaraciones de entrevistados, estos choferes son jóvenes, parientes de dueños de buses y laxibuses que trabajan preferentemente en horarios nocturnos, recibiendo una menor remuneración. También se han registrado prácticas tendientes a eludir la revisión técnica y de gases, utilizando algunas argucias, tales como limpiar los tubos de escape o comprar petróleo refinado importado desde Argentina, para burlar la inspección destinada a detectar vehículos contaminantes.

La presencia reiterada en el sector de estas diversas prácticas informales y algunas acciones ilícitas parece confirmar la hipótesis de que en estos grupos existiría una suerte de subcultura. Ella se caracterizaría por la generación de normas, valores y pautas de conducta que configuran un "espíritu" orientado a burlar algunas normas institucionalizadas, sin que esto pueda asociarse necesariamente con las conductas desviadas, en sentido sociológico del término, sino con "las raíces nacionales de la picardía del chileno". Tal es al menos la justificación que aducen todos los entrevistados respecto de estos usos.

En la década de los 80 ha emergido un oficio que puede ser considerado claramente informal en la medida que no está establecido en la legislación del tránsito público ni obedece a una programación diseñada por los empresarios. Es la actividad de los llamados popularmente "loros" o "sapos" que apareció como respuesta a una necesidad sentida por los choferes de buses, en cuanto a tener información respecto de las distancias que los separan de las "máquinas" de sus propios recorridos como de las de la competencia. Se ubican de preferencia en las cercanías del centro de la ciudad en la Avenida Bernardo O'Higgins entre la Plaza Italia y la Estación Central, en el caso de los recorridos Oriente-Poniente y viceversa, y en las calles San Antonio, San Francisco, San Diego, Bandera y Teatinos, para informar a los choferes que circulan con sus máquinas de Norte a Sur. Sin embargo, también es posible observarlos en otras vías importantes como Providencia, Apoquindo, Bilbao, Recoleta, Independencia y Vivaceta.

Este oficio informal es desempeñado, en su mayor parte, por jóvenes que pertenecen o están vinculados con choferes y empresarios de la locomoción colectiva santiaguina. Generalmente, los "sapos" trabajan haciendo turnos: de ocho a trece o catorce horas o bien de catorce a las veintidós o veintitrés horas. Por excepción algunos desarrollan su actividad todo el día: de ocho de la mañana a ocho o nueve de la noche.

Cada "loro" lleva el registro de diversas variantes de una línea lo que le permite obtener un ingreso suficiente al controlar un mayor número de vehículos. Suele cobrar "por turnos", recibienIo de cada chofer, alrededor de $\$ 50$. Aparentemente, esta modalidad de trabajo es utilizada "especto de los choferes más "compadres" de los "sapos", pues del resto de los conductores "eciben dinero por cada vuelta, en un monto que varía entre 10 y 20 pesos por "dato" o nformación.

De acuerdo a entrevistas realizadas entre diversas personas que desempeñan esta labor en las alles de Santiago, los ingresos fluctúan entre los sesenta y cien mil pesos mensuales, dependiendo le los turnos que realice, de la cantidad de variantes que controle y del lugar en que se ubique.

El tiempo que demora en pasar cada vehículo por el punto en que se localiza "un sapo" es 
anotado cuidadosamente en una pequeña planilla, entregándose el "dato" a los choferes mediante señas que son decodificadas por éstos, subiendo a la pisadera de los buses cuando le corresponde recibir su paga.

De acuerdo a declaraciones de un entrevistado:

El dato sirve para que el chofer consiga más pasajeros, regulando la frecuencia de modo que el que va adelante no le robe minutos al que viene atrás. Cada línea trabaja a su manera, hay algunas que todavía trabajan sin sapos, otros tienen seis, otras tienen uno solo. Eso es relativo, depende de los conocidos que se tenga en las líneas. Uno conversa con los choferes y se instala.

Yo, como había trabajado en la línea, los conocía a todos y todos los que trabajan en esto son del ambiente: amigos, parientes, choferes que chocan sus máquinas y se quedan sin documentos, y así.

Aún cuando en este trabajo predominan las pautas informales, su funcionamiento sigue un orden y una continuidad considerable. Es así como los "loros" trabajan de lunes a sábado regularmente, produciéndose un sistema de reemplazo cuando alguno se ausenta. Este sistema consiste en "vender las máquinas" al reemplazante por el lapso en que el "titular" no se encuentra trabajando.

Es probable que de la regularidad en la entrega de "datos" dependa en gran medida el aporte que los choferes pagan a los "loros" pues siempre es necesario que exista alguien que cumpla esta función;

Sólo se hace un corte para almorzar y se trabaja todos los dias de lunes a sábado. Cuando llueve también se trabaja, siempre hay que estar acá.

En general, quienes desempeñan este oficio están conformes con él subrayando el hecho que trabajan "sin que nadie los mande" y los ingresos que reciben. Sin embargo, se manifiestan preocupados por su situación previsional, estabilidad laboral y las malas condiciones de trabajo.

Esta actividad ha aumentado porque es buena, se gana plata, y hasta da para vicios. Por ejemplo, yo tengo documentos al día y puedo buscar pega de chofer, pero no lo hago porque es mucho problema trabajar con los dueños de micros y aquí gano casi más que los choferes. Lo único malo es que no tengo previsión, pero para la pascua y el dieciocho pedimos aguinaldo. Como uno gana diario hay que sacar las cosas al crédito.

Lo otro fregado es el ruido y el humo. La ropa no dura nada; y en invierno, el frío. Se trabaja duro, pero se come bien.

Muchos de estos trabajadores informales consideran que en el futuro cambiarán de trabajo, para lograr más estabilidad, pues creen que esta actividad es pasajera. Ello probablemente explique la carencia de organizaciones o asociaciones que agrupen a estas personas.

Yo voy a trabajar aqui hasta donde se pueda; hay que pensar en los hijos y la familia, darles seguridad. Aquí se trató de reunir a la gente, hacer un sindicato con los más antiguos, pero no pasó nada.

Cuando aducen que desean lograr un empleo estable, probablemente están evitando comprometerse con una actividad que posee un bajo prestigio social, ya que de acuerdo a la información recopilada, los "loros" entrevistados llevaban entre 2 y 8 años, lo cual no permite calificar este oficio como un trabajo ocasional. Las palabras de un chofer que se encontraba trabajando de "loro", obligado por habérsele cursado un parte, ayuda a ilustrar esta situación:

La pega de chofer es mucho mejor que la de sapo, porque aquí como uno es chofer, está 
incómodo; hay mucha gente que nos conoce, yo llevo más de 16 años manejando, entonces que lo vea el público que lo conoce a uno, da un poco de vergüenza.

La visión que los choferes tienen de esta actividad no es coincidente. Sin embargo, concuerdan en que ellos se han habituado a recibir los datos y consideran que debiera permanecer; lo cual podría interpretarse no sólo por la eficacia funcional del oficio, sino también por la creación de lazos afectivos, que en forma latente contribuyen a la integración social.

El loro es arma de doble filo, porque uno a veces está pagando para que le avise al de atrás, dándole datos chuecos a uno.

En todo caso uno se acostumbra con los sapos. Cuando no están se echan de menos. Uno siempre quiere saber a como va, porque todas las variantes son desordenadas. Al final es bueno; ellos se ganan bien la plata.

Este oficio informal, como puede apreciarse, comparte muchas pautas y normas de la subcultura a la cual se hizo referencia anteriormente. Considerando sus diversas vinculaciones con el sector de transporte de pasajeros es posible afirmar que los llamados "loros" o "sapos" pertenecen a dicho sector, aún cuando poseen características particulares y se encuentren sometidos a ciertas diferenciaciones de status que los distinguen del grupo de choferes y de empresarios. La ausencia de reglamentaciones sobre la actividad de los "loros", así como el apoyo de los choferes pueden ser factores que contribuyan a que este oficio adquiera mayor consolidación y arraigo pese a que hasta el momento no se observan manifestaciones de articulación organizativa.

\section{B. La informalidad en taxis y colectivos}

Como se señaló anteriormente, la ley 18.696 del 31 de marzo de 1988 establece el principio de libertad de recorridos que, de cumplirse en la práctica significaría que ningún área urbana podría ser servida exclusivamente por parte de un empresario o de asociaciones empresariales.

Tal como sucede con la locomoción colectiva, en este sector también se manifiestan argucias encaminadas a controlar paraderos de taxis básicos y recorridos de taxis colectivos que implican una suerte de apropiación espacial de la ciudad y un impedimento al ingreso de nuevos vehículos a puntos ya establecidos y a rutas previamente servidas por otros tax is o colectivos. Para conseguir estos propósitos, los taxistas recurren a eficientes mecanismos de presión y control social consistente en amenazas, "pinchaduras" de neumáticos de los vehículos pertenecientes a los nuevos competidores, topones, robos de accesorios, etc.

En palabras de un entrevistado:

Actualmente, se puede elegir entre ser colectivos o taxi básico y no hay mayores dificultades, salvo el permiso previo. El problema es que se forman grupos que no dejan entrar a otros y hay que pedirles permiso y pagar una cuota de incorporación.

Como puede colegirse, aunque la ley ha flexibilizado en gran medida esta actividad, ya sea que el vehículo se destine a taxi básico o colectivo, desincentivando así la presencia de automovilistas que trabajen informalmente, según un dirigente de la Confederación de Choferes de Taxis, falta una normativa que regule esta actividad y contribuya a otorgarle, a quiénes la ejercen, una razonable estabilidad en el trabajo.

Existe inseguridad laboral para los choferes de taxis. El que no tiene un auto está expuesto a la cesantia, y así existe muchísima rotación de choferes.

Hay una gran irregularidad en cuanto a la celebración de contratos de trabajo entre los dueños de taxis y los choferes. Tampoco existe un horario fijo, por lo que se trabaja doce $y$ catorce horas diarias. 


\section{REVISTA DE SOCIOLOGIAA}

En la práctica cuando no se celebran contratos de trabajo entre los empresarios dueños de los automóviles y los taxistas, se acude a acuerdos verbales conviniéndose la ganancia diaria del dueño del vehículo y la parte que le corresponde al conductor. Además, los dirigentes consultados han manifestado su preocupación por las duras condiciones con que los conductores de estos móviles realizan sus labores en el intenso y caótico tránsito de la capital y por el riesgo que implica contraer una enfermedad o sufrir un accidente.

Si un colega se enferma de ciática o de lumbago, fregó no más. Un oído generalmente está más expuesto, porque llevamos el vidrio abierto igual que el brazo. No tenemos un sistema que permita prevenir las enfermedades profesionales. Si hay problema con el vehículo o con la salud, uno queda cesante.

Una modalidad informal que asume el transporte de pasajeros en Santiago, mediante colectivos y taxis básicos, está constituida por los traslados de personas que se efectúan sin entregar los boletos, en el caso de los colectivos, y sin el registro del taxímetro, en los taxis básicos. A pesar que el Ministerio de Transporte y Comunicaciones impone la obligatoriedad de estas conductas, ellas se eluden mediante acuerdos informales con los pasajeros, rebajando las tarifas o simplemente no dando el correspondiente boleto. En cuanto a la fal ta de registro del taxímetro, también suelen ocurrir acuerdos verbales entre el conductor y el pasajero, lo que sucede más frecuentemente en los trayectos largos.

Si bien estas acciones no se enmarcan en las normas institucionales establecidas no pueden considerarse como expresiones de transporte informal, puesto que los taxistas han recibido un reconocimiento estatal, cumplen con las normas técnicas de revisión periódica y sus vehículos se encuentran uniformados por medio de los colores negro y amarillo.

Una manifestación típicamente informal, en cambio, estaría representada por automóviles, camionetas y furgones particulares que se dedican a transportar pasajeros en Santiago de manera encubierta y muy difícil de detectar.

De acuerdo a antecedentes entregados por algunos choferes de taxis, asociaciones de microbuseros y funcionarios del Ministerio de Transporte, esta nueva modalidad habría surgido durante los últimos años.

Una evidencia concreta es el traslado de personas, mediante furgones, especialmente que son trasladados hasta sus domicilios con sus paquetes desde salidas de supermercados u otros grandes establecimientos comerciales, actividad ejercida de preferencia por dueñas de casa, como una forma de colaborar al ingreso familiar, sin que por cierto hayan solicitado la autorización correspondiente para usar sus automóviles como taxis. Otra modalidad consiste en el traslado de pasajeros por parte de conductores de vehículos particulares, que suelen producirse a tempranas horas en determinadas avenidas de intenso tráfico, contactando a su clientela mediante juego de luces y cobrándoles una tarifa inferior a la de los "taxis colectivos".

Las vías donde se registra una mayor ncidencia de esta informalidad en el transporte son las avenidas Vicuña Mackenna y Gran Avenida, hacia el Sur; Las Condes hacia el Oriente y la Carretera Panamericana hacia el Norte de la Capital.

Estas actividades son consideradas por las asociaciones de taxistas como competencia desleal, aunque reconocen que no representan un número significativo de vehículos ni acarrean un perjuicio notorio a la rentabilidad del sector. Con todo cuando son sorprendidos, los taxistas desalientan estas acciones mediante amenazas.

Puede citarse además, otra actividad que ha adquirido cierta presencia en la ciudad de Santiago, representada por el transporte de escolares que son recogidos desde sus domicilios y trasladados hasta sus respectivos planteles educacionales y que son efectuados generalmente en 
vehículos tipo furgones o minibuses. Para que este tipo de transporte se realice dentro del marco legal debe tramitarse el permiso respectivo ante el Ministerio de Transporte para iniciar sus actividades y pagar impuestos por renta presunta, de acuerdo a la tasación del vehículo efectuada por el Servicio de Impuestos Internos. Además, debe poseer el seguro obligatorio y contar con la revisión técnica y de gases. Por último el conductor debe poseer licencia "clase A" y el vehículo estar claramente identificado, utilizándose el color amarillo para cubrir su carrocería y letreros indicativos de la función a que está destinado. En los hechos, sin embargo, se ha detectado un número significativo de vehículos que no cuentan con los permisos respectivos ni cumplen con las medidas de seguridad mínimas para el transporte de escolares, constituyendo una modalidad claramente informal o ilegal.

Al respecto la Confederación de Transporte de Pasajeros, a través de una declaración pública cmit ida el día 6 de octubre de 1989, manifestó que estos vehículos de trasporte escolar representa un serio riesgo para las personas, ya que poseen una carrocería deficiente y carecen de doble rueda por parte trasera. Se agrega además que la participación de esta forma de transporte en el mercado constituye una competencia desleal que está arruinando a los empresarios de autobuses y taxibuses.

Esta modalidad de transporte se concentra en las comunas del sector oriente de la Capital, donde residen las familias de más altos ingresos.

Finalmente, cabe señalar que el transporte de pasajeros mediante taxis y colectivos se ha hecho más heterogéneo, en la medida que las características generacionales del sector se han ido perdiendo al incorporarse, especialmente en épocas de crisis, personas que desempeñaban actividades profesionales diversas y que se encontraban cesantes.

Según declaraciones de un dirigente del rodado, los profesionales llegaron a representar el $50 \%$ de los taxistas capilalinos en el período de la recesión económica, mientras que en la actualidad su incidencia se calcula en alrededor de un tercio, contribuyendo a congestionar las vías capitalinas y a disminuir la rentabilidad de quienes desempeñan este oficio regularmente.

A juicio de un entrevistado:

"Si hubieran posibilidades concretas de trabajo para los profesionales, saldría entre un $30 \%$ y $40 \%$ de los taxistas".

\section{CONCLUSIONES Y SUGERENCIAS}

La investigación efectuada permite extraer preliminarmente un conjunto de conclusiones y formular algunas sugerencias de carácter general respecto del transporte de pasajeros en la ciudad de Santiago.

En principio se podría postular que este sector informal tiene una influencia poco significativa desde un punto de vista cuantitativo, tanto por el número de personas que pertenecen a él como respecto al peso economico que posee sobre el total de las actividades del transporte realizados en la Capital.

Pese a ello, las evidencias acumuladas permiten afirmar que analizando la informalidad desde un enfoque más amplio, que no sólo involucre la presencia de segmentos sociales específicos, sino que también determinados comportamientos y actividades, su importancia cualitativa es enorme, generando variadas consecuencias que pueden tener una considerable influencia sobre los procesos de racionalización y modernización que involucran al sector transporte en la actualidad.

A partir de los datos obtenidos se pueden clasificar las actividades informales registradas en este sector en los siguientes tipos principales. 
a) Traslado de personas fuera de la Capital producto de recorridos no habituales de buses y taxibuses.

b) Recorridos al margen de las rutas formales dentro de la capital con ocasión de eventos.

c) Actividades de regulación del flujo del transporte colectivo a través de "sapos" o "loros".

d) Actividades de control de paraderos y rutas.

e) Movilización de personas en vehículos particulares no autorizados.

f) Fijación informal de tarifas entre conductor y cliente.

Se pudo constatar también acciones que escapan del ámbito informal mismo y que representan conductas francamente ilegales. Entre ellos destacan las burlas a las revisiones técnicas y de gases, la conducción de vehículos por choferes que no poseen licencia "Clase A" y el incumplimiento de algunas obligaciones de la legislación laboral. Muchas veces quienes incurren en estas irregularidades aprovechan la falta de control administrativo y policial, orientándose por pautas subculturales fuertemente arraigadas.

Todos estos segmentos, actividades y acciones si bien muestran una alta heterogeneidad y complejidad, expresándose de múltiples maneras en las actividades de transporte, no logran configurar un sector paralelo, como sucede en otras ciudades latinoamericanas. Ello no significa que las actividades informales no posean influencia sobre la dinámica referida al uso de la ciudad; por el contrario, el mundo informal aparece como uno de los patrones que inciden en la intensidad del flujo de tránsito en determinadas vías, el control y apropiación de ciertas rutas y el dominio sobre áreas urbanas y paraderos.

La prevalencia de prácticas informales también da origen a determinadas normas y controles sociales que afectan considerablemente aspectos tales como: la configuración de recorridos de buses, taxibuses y taxis colectivos a través de requisitos informales, pero de hecho de carácter obligatorio, que deben cumplir los que desean ingresar a una línea. Estos efectivos mecanismos de presión social no sólo se ejercen al interior de las líneas y variantes, sino que tienden a producir consecuencias importantes cuando se manifiestan a través de la acción de grupos organizados de personas, pudiendo distorsionar el sentido de ciertas políticas y programas, o generar notables resistencias que hagan impracticable las regulaciones emanadas de la autoridad.

La identificación de prácticas monopólicas en el sector tendientes a controlar las tarifas así como la reacción organizada frente a medidas que afectan sus intereses, son expresión de la fuerza que han ido adquiriendo éstas interacciones informales al interior de grupos formalizados.

Cabe señalar que la aplicación de los principios de la libre concurrencia al quehacer del transporte ha generado efectos positivos y negativos. Por una parte ha significado impulsar de una manera dinámica el desarrollo de nuevos recorridos de buses y taxibuses, flexibilizando las actividades del transporte de pasajeros mediante la eliminación de un conjunto de trabas burocráticas. Por otra se han generado y agudizado problemas, ya que si bien la libertad de recorridos ha permitido dar servicios a amplios sectores poblacionales ubicados en la periferia urbana, ha hecho recrudecer la congestión vehicular, incrementando la contaminación del aire en la ciudad de Santiago, contribuyendo al desorden y a las superposiciones de líneas del transporte público que se observa en la actualidad en varias avenidas de la capital. El caso más evidente es el de la Avda. Libertador B. O'Higgins, arteria por la cual circulaba antes de la licitación de recorridos el 70\% de los buses y taxibuses que recorren la ciudad de oriente a poniente y viceversa, a pesar que bajo al la tiene su recorrido el metro.

La tendencia que se observa en la actual administración en orden a establecer un sistema integrado de transporte urbano, a través de un creciente aumento en las normativas y disposiciones reglamentarias, sin que el Estado disponga de los recursos humanos y técnicos indispensables para 
su implementación y control puede implicar una reacción hacia el polo de la informalidad. Este riesgo se fundamenta principalmente en las características subculturales propias de los gremios de transportistas terrestres quienes, ante un incremento en las restricciones, obligaciones y condicionamientos para efectuar la actividad pueden canalizar sus intereses a través de nuevos resquicios, argucias, comportamientos ilegales o aumentar el repertorio de prácticas informales retrasando o imposibilitando la necesaria modernización del sector.

A la luz de los resultados de esta indagación pueden plantearse las siguientes sugerencias:

En primer lugar es necesario reexaminar el actual sistema de remuneraciones de los conductores, en función de estimar la factibilidad de que en sus ingresos predomine cl sueldo fijo por sobre el porcentaje derivado del corte de boletos. Ello implicaría contribuir a eliminar las prácticas del "tony" o "enchufe", las irregularidades en la entrega de boletos a los usuarios y la competencia frenética en las vías de Santiago, con la natural incidencia en los accidentes de tránsito y en el incremento de la congestión vehicular.

En esta perspectiva, la actividad de los "sapos" o "loros" carecería de sentido y eventualmente podría desaparecer o derivar en su formalización, al ser contratados por los propios empresarios, asimilándose a la antigua actividad del denominado "relojero de línea".

Respecto de las relaciones laborales, las autoridades deberían aumentar su preocupación por el cumplimiento de los contratos de trabajo de los choferes, por cuanto el actual sistema resulta fácilmente vulnerable. Ello implica necesariamente una racionalización de las formas de control ejercida por la Inspección del Trabajo, las cuales no se han adaptado a la dispersión y heterogeneidad que presentan los empresarios transportistas.

Por otra parte, debiera propiciarse una carrera del conductor orientada a su profesionalización, aumentar la estabilidad en el empleo y gencrar un sistema de ascensos y promociones. En el caso de los empresarios sería recomendable que, a traves del Ministerio respectivo y de organismos como el sENCE, se impulsaran acciones para su capacitación y perfeccionamiento, privilegiándose las áreas de gestión y administración de recursos, en orden a reforzar actitudes modernas, visión de futuro y crear conciencia de la responsabilidad social que les corresponde.

Todas estas proposiciones se inspiran en la idea central de crear un conjunto de mecanismos coherentes que faciliten la integración de segmentos sociales, actividades permanentes y acciones esporádicas de carácter informal, contribuyendo a mejorar los servicios de transportes que se prestan al habitante de Santiago, corrigiendo las contradicciones existentes y aprovechando las potencialidades y energías creativas de la informalidad.

\section{BIBLIOGRAFÍA}

AmStrong, Alan (1987): Sistemas de Transporte Páblico Urbano. Documento Técnico del Banco Mundial № 525 , Washington DC.

DE Soto, Hernando (1986): El otro sendero. Ed. El Barranco, Lima.

Jiario El Mercurio (1989): 9 de octubre.

Diario El Mercurio (1989): 23 de septiembre.

IETHANOBIC, Pedro (1987): Locomoción Colectiva: de la liberalización al control 1978-1986. Rev. Economía y Administración, № 57, Santiago.

Matos MAr, Josê (1985): Desborde popular y crisis del Estado. Instituto de Estudios Peruanos, Lima.

Ministerio de Transporte y Comunicaciones (1976): Resolución 1.108 del 24 de septiembre.

Winisterio de Transporte y Commicaciones (198): Resolución $N^{o} 1$ del 3 de enero.

Winisterio de Transporte y Comunicaciones (1988): Ley No 18.696 del 31 de marzo.

Winisterio de Transporte y Comunicaciones (198): Decreto $N^{0} 124$.

S1.MA, DiEGo (1987): La informalidad, lo popular y el cambio Social Cuademos DESCO No 8, Lima. 


\section{REVISTA DE SOCIOLOGÍA}

PARK, RoBert (1928): Human Migration and the Marginal Man. American Journal of Sociology, Vol. 33, mayo. PREALC (1981): Sector Informal. Funcionamiento y Políticas. Buenos Aires.

UGARTE C. Y. VATTER (1987): ¿Existe un Cartel en el transporte colectivo de Santiago? Rev. Economía y Adrministración № 62, Santiago. 